\title{
EXPLORING A LEADERBOARD ALTERNATIVE IN A GAMIFIED MOBILE APP FOR MUSIC LEARNING
}

\author{
Heather J.S. Birch ${ }^{1}$ and Clare Brett ${ }^{2}$ \\ ${ }^{I}$ Tyndale University College \\ ${ }^{2}$ Ontario Institute for Studies in Education, University of Toronto \\ Toronto, Ontario, Canada
}

\begin{abstract}
This paper describes the use of an Android app, PracticeCactus, to support independent piano practice in the context of one music teacher's private studio through a feature known as "Daily Practice Goal" (DPG) notifications. DPG notifications are positioned here as a type of alternative to a traditional leaderboard within a gamified learning environment. The DPG notifications were a means of gamifying independent practice, thereby facilitating social community support that is in contrast to the isolation and individualistic learning that is sometimes characteristic of independent musical instrument practice. Piano student participants, ages 10 through 15, made use of the mobile app for 20 weeks, and their usage patterns and experiences of the DPG notifications are explored here as a way of illuminating how social interactions may be supported and encouraged during independent practice between weekly lessons.
\end{abstract}

\section{KEYWORDS}

m-Learning, Music Education, Piano Practice, Social Interactions

\section{INTRODUCTION}

This paper describes the use of a mobile app to support independent piano practice in the context of one music teacher's private studio through a feature known as "Daily Practice Goal" (DPG) notifications. DPG notifications are positioned here as a type of alternative to a traditional leaderboard within a gamified learning environment. The DPG notifications were a means of gamifying independent practice, thereby facilitating social community support that is in contrast to the isolation and individualistic learning that is sometimes characteristic of independent musical instrument practice. Piano student participants, ages 10 through 15, made use of a mobile app known as PracticeCactus, and their usage patterns and experiences of the DPG notifications are explored here as a way of illuminating how musical skill development may be supported and encouraged during independent practice between weekly lessons. This specific consideration of DPG notifications is one part of a larger study that examined social interactions more broadly in the context of the PracticeCactus app.

In the context of studio music learning, practicing regularly between lessons is important for developing musical skills, confidence, and technical proficiency on an instrument (Bloom \& Sosniak, 1985; Bonneville-Roussy \& Bouffard, 2015; Ericsson, Krampe, \& Tesch-Römer, 1993). Therefore, the importance of independent musical practice cannot be minimized. But music students often report that they sometimes find independent practice to be isolating, enigmatic, and boring (Ericsson et al., 1993; Jørgensen, 2000). During independent practice, students can become discouraged, forget what they are supposed to be practicing, and forget how to practice it (Jensen \& Frimodt-Møller, 2015). Additionally, studio music teachers consistently report that students under-practice or practice ineffectively (McPherson \& Renwick, 2001; Oare, 2012); this may be due to the lack of excitement inherent in independent practice, or it may be due to other factors, such as busy schedules or lack of parental support (Upitis, Abrami, Brook, \& King, 2017). Since practice is necessary for developing skill, it is important to consider students' experiences of such practice. 
One of the ways in which PracticeCactus was designed to mitigate against common problems with independent practice, and to facilitate social interactions, was to make independent practice visible and known. In other words, while the students in this particular piano studio likely knew that their colleagues were practicing, the app was designed to provided tangible evidence of this practice. One way to make musical practice visible would be to implement a leaderboard that showed students' accumulated number of practice minutes and listed students in order of who practiced most to who practiced least. However, the PracticeCactus app used an alternative approach to sharing practice in a leaderboard format for three reasons. First, research reporting the effects of leaderboards is often focused on whether students' motivation or achievement levels are somehow affected. In the context of this research study, this was not the main goal; rather, the idea of sharing practice was meant, primarily, to foster social interactions. Second, research reporting the effects of leaderboards is mixed. Research in workplace and higher education contexts shows that leaderboards have positive effects including facilitating more lofty goal setting, and motivating students to engage more frequently with the material to be learned (Fotaris, Mastoras, Leinfellner, \& Rosunally, 2016; Landers, Bauer, \& Callan, 2017). However, many studies in these same contexts reveal mixed results concerning leaderboards, with some participants expressing positive responses, and others finding the leaderboard to be a negative experience, and expressing their dislike and uneasiness (Domínguez et al., 2013). Leaderboards have been demonstrated to have an effect on performance in academic settings, either negatively or positively, depending on the individual perspective of each person vying for a position on the board (Christy \& Fox, 2014; Domínguez, Saenz-de-navarrete, \& Pagés, 2014). Therefore, due to the potential for negative reactions to a leaderboard, PracticeCactus was not designed with such a feature. A third reason not to incorporate a traditional leaderboard within PracticeCactus is that in a previous research study with music students of this age group (Birch \& Woodruff, 2017), a traditional leaderboard was shown to frustrate and confuse some of the participants. Therefore, the risk of using a traditional leaderboard which depicted students in order of achievement was decided against. Erring on the side of caution, another form of sharing progress with the app was implemented, i.e. the DPG notification feature.

Investigating how a digital tool-and in particular, a mobile app — can support musical instrument practice is important because music students are already using their mobile devices to support them during independent practice, largely to look up YouTube videos as exemplars for their playing and to record their own playing in order to listen and reflect (Upitis, Brook, Abrami, \& Varela, 2014). Therefore, an investigation into how an app specifically designed to enhance learning in the context of private music study is essential for informing current student practices, and for exploring an alternative to a traditional leaderboard for sharing student progress within a music learning community.

\section{PRACTICECACTUS: A DESCRIPTION OF THE APP}

The PracticeCactus mobile app was collaboratively designed by a group that included me, the researcher, a team of piano students, their parents, piano teachers, user-experience researchers, and computer programmers. The design methodology employed was participatory design, meaning that all stakeholders have a voice affecting the direction of the design and development of a solution to a design problem (Steen, 2013). As a result, the PracticeCactus app has three major functions that were designed to address the students' descriptions of independent practice as lonely and isolating. The design functions that mitigate against those negative descriptions are the technical supports for sharing practice, listening to practice, and quantifying practice. This paper will specifically report on the functionality of listening to practice and quantifying practice in the context of DPG notifications, and the resulting experiences of the piano students.

\subsection{Listening to Practice}

When the PracticeCactus app is active on a mobile device, through an embedded acoustic analysis module it automatically detects student piano. The student designers of the app insisted that they did not want this app to record their practice sessions so that the teacher might check in at any moment and hear their practice. The app does not track which songs are practiced, in which order, or for how long. Neither does the app assess whether a student plays correct rhythms or notes. Rather, it most simply counts up the number of minutes a student has practiced during each 24-hour period. 


\subsection{Quantifying Practice}

Based on what it "hears," the app generates notifications on the Community page every time a student meets their self-determined goal of number of minutes of piano practice per day. Length of a piano-practice session, although an easily quantifiable measure that could be used to characterize a session, is not universally applicable to students of different ages and skill levels. An expected piano practice session length for a beginning student may be ten minutes, while an advanced student may be working toward an hour or more of practice each day. Therefore, the quantifiable measure of the Daily Practice Goal (DPG) was defined and used to make students' practice sessions tangible and shareable and to establish a common language in the PracticeCactus community that everyone could relate to and achieve. When a student in the study reached their DPG, the app automatically created a post, letting others know (See Figure 1). No information was revealed about the actual length of time of each student's Daily Practice Goal. The series of DPG posts about students meeting their daily goals, then, was not intended to invoke comparisons, but rather to provide a tangible picture of the efforts of individuals, thus highlighting those efforts and allowing them to become part of an interaction, as opposed to those efforts remaining as isolated experiences.

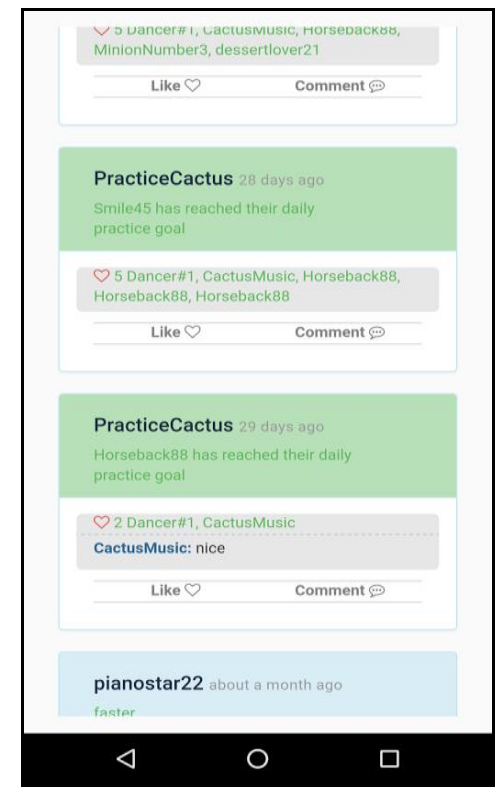

Figure 1. Screenshot of the app posting Daily Practice Goal (DPG) Achievements

\section{THEORY}

As a whole, the social sciences are largely in consensus on the perspective that society and culture are enacted through a series of social interactions (Regelski, 2016). Piaget's focus might be said to rest with society's influence on learners, while Vygotsky emphasizes culture as the context in which social interactions take place (Cole \& Wertsch, 1996). Ultimately, social constructivism is concerned with what students learn and the process they undertake in order to do this learning (Cobb, 1994). The ideas of social constructivism are useful in the context of the current research study because, even though independent musical instrument practice is by nature done independently, the artifacts and experiences that are developed through social processes continue to support and influence learners, even when they are alone. So then, the social aspects of the process of learning operate not only when people are in a social setting. 


\section{METHOD}

This paper describes a case study, as outlined by Stake (1995), in that the particularities and complexities of a single case exist as an opportunity to understand the activity within that case, which is an ideal approach in the context of the study of people and their behaviour (Yazan, 2015). The case was bounded by a length of 20 weeks and engaged 18 participants; there were nine males and nine females ranging in age from 10 to 15 years of age. Participants had played the piano for between three and twelve years and were studying at levels two through nine of the Conservatory Canada piano curriculum. These participants were invited to use the app in the context of their independent practice between weekly piano lessons with their teacher.

\section{DATA COLLECTION AND ANALYSIS}

Throughout the data collection period, as the researcher, my modus operandi was to be in the context where the students were (i.e., logged in regularly to the PracticeCactus app) to observe the students' behaviour and to make decisions, through analysis and synthesis, while maintaining an awareness of my own subjectivity (Stake, 1995). Within this study, the following four sources were used to collect data about the case: (a) interviews; (b) music-sharing sessions; (c) field notes; and, (d) student-created artefacts. Content analysis - that is, analyzing the content of interviews and observations, was conducted, whereby I, as the researcher, identified, coded, and categorized the key patterns within the data (Patton, 1990). Some of the data were winnowed in order to preserve the most relevant data (Morse, 2018; Wolcott, 1990).

\section{RESULTS}

\subsection{Frequency and Patterns of Usage}

Throughout the period of this 20-week study, 694 practice sessions were recorded by students. The students were not instructed as to how often they should use the app but were simply given a device and told how to create a PracticeCactus account. Some students used the app multiple times per week, whenever they practised, while others decided to use it only occasionally throughout the course of the study. Some students articulated that the app was useful to them by way of the embedded acoustic analysis module, insofar as it generated DPG notifications in the community. These students explained that they wanted the community, i.e. their piano-playing peers, to know they were practising.

\subsection{Daily Practice Goal}

Daily Practice Goal notifications were posted in the Community when students achieved a certain number of minutes of practice per day. In this way, students created an artefact in the PracticeCactus environment indirectly since the app automatically posted on their behalf. Throughout the research study, students reached their Daily Practice Goal (DPG) 81 times.

Reactions to seeing others reach their DPG included feeling reassured, motivated, and competitive, as well as feeling happy for and supportive of peers. As a student with the username pianoman 10 recounted, for him, seeing a person reach their DPG made him feel happy for that person, but it did not really affect him too much, since he did not know if their practice goal was five minutes or five hours. "I care a little bit but probably not the same feeling as scoring a [hockey] goal because it's, like, a rush, you know, really happy but I'm still happy for that person." As described by hockeyman, seeing DPG notifications was reassuring, "because it would tell you that if other people can do it then you can do it too... So if you see other people doing it then you're like, oh, yeah! You can do it." As archer explained, it "motivated me to achieve my daily practice goal if I hadn't done so already, partially because I wanted that same feeling of satisfaction once I completed my goal and partially because I'm a pretty competitive person, so to see other people achieving their goals makes me want to achieve even greater." 
Once DPG notifications were posted in the community, students had the opportunity to listen to those recordings and to respond by "liking" or adding a comment. One of the behaviours that almost all students engaged in was to "like" posts that appeared on the Community page of the app. When the app posted that someone received their Daily Practice Goal (DPG), these types of posts received a total of 70 "likes," or 35\% of all the "likes" given in total. Perhaps not surprisingly, students "liked" others' posts and DPG notifications more often than they "liked" their own. Reasons students "liked" a post were to show appreciation, to support their peers' beliefs, values, hard work, and growth, and when they were unsure of what to say in a comment. Students agreed about positive encouragement; if they got "likes," or people gave them a compliment, then this helped them feel good and motivated them to keep practicing.

MinionNumber3, a 13-year-old male participant, made frequent use of DPG notifications as a springboard for introducing social interactions to the PracticeCactus environment, both through posting ironic comments and "liking" posts multiple times. He often created content or left comments that invited a response from others. Here are some examples of the comments he left on Daily Practice Goal notification posts, shown in Figure 2.

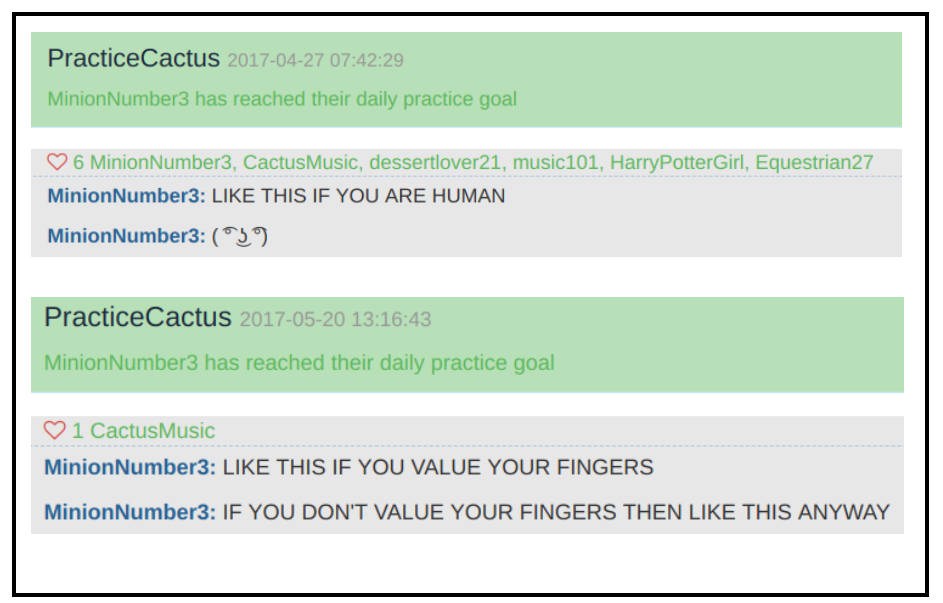

Figure 2. Screenshots of humorous comments posted by MinionNumber3

\section{DISCUSSION}

\subsection{Frequency and Patterns of Usage}

Throughout the 20-week period of the study, students chose to make use of the app at varying levels, with some using PracticeCactus frequently and others, infrequently. Students chose to use the app multiple times a week, once per week, or every few weeks. Since there was initially no direction given to students about how often they should use the app or how they should participate, this is an example of providing an opportunity for active music making completely on the participants' own terms in order to open, deepen, and widen the space for contributions (Camlin, 2014; Wegerif, 2012).

Reasons to share user-generated content in an online space are theorized by Waldron (2013b) as having a space for people to have discussions and to learn from the musical experiences of others who have similar interests. While a DPG post in itself is not a discussion, it presents an opportunity for a social interaction in that others may decide to read it, or additionally, to "like" or comment on it. Other recent work by Pak (2014) distinctly conceptualizes the idea of sharing in today's world, not necessarily in terms of reasons why people decide to share or not to share. Rather, since the terms "online" and "offline" are less and less meaningful now due to the ability to have constant access to connected devices, the more useful distinction becomes the choice between "shared" and "private." Thus, the question is not whether to go online and share or stay offline and decide not to share, but instead how to manage, store, and share one's personal data. As Pak (2014) explains, real meaning is found in how shared personal data connects to others' data and the value 
others find in your data. In the context of PracticeCactus, then, the sharing of their practice and others' responses to that practice functioned as opportunities for students to control their own expression of their personal data and to express that they found value in what had been shared.

\subsection{Daily Practice Goal}

The acoustic analysis module within the app that "listened" for piano playing allowed students to add meaningful signs to their learning environment in the form of Daily Practice Goal (DPG) postings (Gee, 2005). When the students reached their DPG and the app posted a notification for others to see, the students were adding content to the learning space. As the students described, seeing others reach their DPG was a type of reminder that allowed them to acknowledge that others were practising just as they were. The DPG notifications, then, were a group of signs in the community (Gee, 2005) that students engaged with through reading, "liking," and commenting on them. Thus, the posting of the DPG achievements allowed for individual practice sessions to result in a social interaction, i.e., to be "liked" or commented on by others. Even though not all DPG posts resulted in an explicit social interaction (i.e., not all of these posts received "likes" or comments), the students perceived that their peers "saw" that they were practising. Whereas their practice sessions were once private, they now became shared. Even without a direct social interaction, the DPG posts reinforced new relationships and participatory practices among the students in two ways. First, a new, shared practice was added to the students' repertoire of external signs within their learning context, i.e., students let each other know when they were practising. Second, one of their internal signs (i.e., practising their instrument) shifted from being an intangible sign that unified them primarily by assumption to a tangible and shared common sign that unified them based on direct knowledge of their affinity group habit of practising piano.

As explained, Daily Practice Goal posts were external signs created by users within the affinity space, although, admittedly, the app auto-posted these achievements and there was no explicit action required by the user. There was a specific action of practising the piano that triggered the post and thus indirectly added a sign into the affinity space. Where students did exercise direct control over DPG posts was through choosing and adjusting the number of minutes of piano practice that would trigger the achievement of their goal. This gave them control over the frequency of posts about them; students did, then, have the ability to manipulate the signs within the space (Gee, 2005).

\section{CONCLUSION}

Most music educators acknowledge that young music learners in the 21st century have unprecedented access to music. They have opportunities to engage even more deeply with music than simply just listening (Allsup, Westerlund, \& Shieh, 2012; Jenkins, 2006; Tobias, 2014). Digital technology allows them to produce music and engage socially around music (Gee, 2010; Jenkins \& Deuze, 2008; O'Hear \& Sefton-Green, 2004). Traditional barriers of finances, technology, advanced knowledge of music theory, or access to professional producers, distributors, and recording labels, are no longer acting as such major barriers against creating and sharing music (McGrath, Chamberlain, \& Benford, 2016; Partti, 2014). Music-sharing sites, as well as cloud-based storage services and mobile devices allow for music to be easily shared with an audience of any size (McGrath et al., 2016).

Mobile app developers can consider the features and design of the PracticeCactus app as a model of a technology designed to foster opportunities for students to interact with one another throughout the week between their music lessons and to provide students with increased independence in making decisions about their own music learning. Knowledge of this research study and the benefits to students of such learning may empower developers to intentionally avoid developing music-learning apps based on limited conceptualizations of music learning that reduce music learning to exercises in naming notes or identifying the correct piano keys. As explained by Scardamalia and Bereiter (2008), educational technology is seldom neutral, but, rather, through its available features usually facilitates some actions more readily than others and thus encourages those actions. As studio music teachers broaden their practice through the use of digital tools (Upitis, Abrami, \& Boese, 2016; Upitis, Brook, Abrami, \& Varela, 2014), they will need technologies to use with their students that facilitate and encourage meaningful music learning in socially and culturally relevant 
contexts. Along with this research, other studies about informal, online musical sharing spaces such as Mikseri (Partti \& Karlsen, 2010) and the Banjo Hangout (Waldron, 2013a) can provide models for consideration. Studies focused on iSCORE and Cadenza also provide insight into the types of digital tools that students will engage with and that will promote music learning (Brook \& Upitis, 2015; Upitis \& Abrami, 2016). Informed with this knowledge, developers can engage in intentional design for connected music learning and ideally create apps that teachers will actually use with their students, perhaps on an ongoing basis.

Future research could usefully be design-based, wherein students have input regarding the features of PracticeCactus and inform a responsive developer team who can implement their suggestions in iterative stages. As new features are added or changed, students can provide direct feedback as to how changes have influenced their experience of learning. Studies such as this would provide more information to mobile app developers interested in creating apps for facilitating music learning. Knowing which features maximize opportunities for music learning and encourage students to use the app would inform their future development projects in ways that support both music students and teachers. Ultimately, app designs focused on facilitating social interactions in the context of music learning will prevent students from having to experience individual musical instrument practice as a lonely and isolated endeavour.

\section{REFERENCES}

Allsup, R. E., Westerlund, H., \& Shieh, E. (2012). Youth culture and secondary education. In G. E. McPherson \& G. F. Welch (Eds.), The Oxford Handbook of Music Education (Vol. 1, pp. 460-475). New York, NY: Oxford University Press.

Barden, O. (2016). Heterotopic affinity spaces. Power and Education, 8(3), 222-236.

Birch, H. J. S., \& Woodruff, E. (2017). Technical exercise practice: Can piano students be motivated through gamification? Journal of Music, Technology, \& Education, 10(1), 31-50.

Bloom, B. S., \& Sosniak, L. (1985). Developing Talent in Young People. New York, NY: Ballantine Books.

Bonneville-Roussy, A., \& Bouffard, T. (2015). When quantity is not enough: Disentangling the roles of practice time, self-regulation and deliberate practice in musical achievement. Psychology of Music, 43(5), 686-704.

Brook, J., \& Upitis, R. (2015). Can an online tool support contemporary independent music teaching and learning? Music Education Research, 17(1), 14-34.

Camlin, D. A. (2014). Whatever you say I am, that's what I'm not: Developing dialogic and dissensual ways of conceiving of and talking about community music. In Proceedings of International Society for Music Education (pp. 1-8). Glasgow, SCT: Higgins Kelly McKay \& Higham.

Campbell, P. S. (1991). Lessons from the world: A cross-cultural guide to music teaching and learning. New York, NY: Schirmer Books.

Christy, K. R., \& Fox, J. (2014). Leaderboards in a virtual classroom: A test of stereotype threat and social comparison explanations for women's math performance. Computers \& Education, 78, 66-77. https://doi.org/005

Daniel, R. J., \& Parkes, K. A. (2015). Assessment and critical feedback in the master-apprentice relationship: Rethinking approaches to the learning of a musical instrument. In Assessment in Music Education: From Policy to Practice (pp. 107-124). Basel, CH: Springer International Publishing.

Davidson, J. W., \& Jordan, N. (2007). "Private teaching, private learning": An exploration of music instrument learning in the private studio. In L. Bresler (Ed.), International Handbook of Research in Arts Education (pp. 729-754). Dordrecht, NL: Springer Netherlands.

Domínguez, A., Saenz-de-Navarrete, J., de-Marcos, L., Fernández-Sanz, L., Pagés, C., \& Martínez-Herráiz, J.-J. (2013). Gamifying learning experiences: Practical implications and outcomes. Computers \& Education. Retrieved from http://resolver.scholarsportal.info/resolve/03601315/v63inone_c/380_glepiao

Domínguez, A., Saenz-de-navarrete, J., \& Pagés, C. (2014). An empirical study comparing gamification and social networking on e-learning. Computers \& Education, 75, 82-91.

Draper, P. (2007). Music two-point-zero: How participatory culture is reclaiming knowledge, power and value systems from the inside out. In Proceedings of Twilight Lecture Series (p. 19). Nathan, QLD: Griffith University.

Ericsson, K. A., Krampe, R. T., \& Tesch-Römer, C. (1993). The role of deliberate practice in the acquisition of expert performance. Psychological Review, 100(3), 363-406.

Fotaris, P., Mastoras, T., Leinfellner, R., \& Rosunally, Y. (2016). Climbing up the leaderboard: An empirical study of applying gamification techniques to a computer programming class. Electronic Journal of E-Learning, 14(2), 94-110. 
Gee, J. P. (2005). Semiotic social spaces and affinity spaces: From the age of mythology to today's schools. In D. Barton \& K. Tusting (Eds.), Beyond Communities of Practice (pp. 214-232). Cambridge, UK: Cambridge University Press.

Gee, J. P. (2010). New digital media and learning as an emerging area and "worked examples" as one way forward. Cambridge, MA: MIT Press.

Jenkins, H. (2006). Fans, bloggers, and gamers: Exploring participatory culture. New York, NY: New York University Press.

Jenkins, H., \& Deuze, M. (2008). Convergence culture: Where old and new media collide. The International Journal of Research into New Media Technologies, 14(1), 5-12.

Jensen, K., \& Frimodt-Møller, S. (2015). An integrated playful music learning solution. In Universal Access in Human-Computer Interaction. Access to Learning, Health and Well-Being (pp. 462-471). Los Angeles, CA.

Jørgensen, H. (2000). Student learning in higher instrumental education: Who is responsible? British Journal of Music Education, 17(1), 67-77.

Landers, R. N., Bauer, K. N., \& Callan, R. C. (2017). Gamification of task performance with leaderboards: A goal setting experiment. Computers in Human Behavior, 71, 508-515. Retrieved from http://dx.doi.org/10.1016/j.chb.2015.08.008

McGrath, S., Chamberlain, A., \& Benford, S. (2016). The grime Scene: Social media, music, creation and consumption. In Audio Mostly. Norrkoping, SE.

McPherson, G. E., \& Renwick, J. M. (2001). A longitudinal study of self-regulation in children's musical practice. Music Education Research, 3(2), 169-186.

Morse, J. (2018). Reframing rigor in qualitative inquiry. In N. K. Denzin \& Y. S. Lincoln (Eds.), The Sage Handbook of Qualitative Research (pp. 796-817). Thousand Oaks, CA: Sage Publications, Inc.

O'Hear, S., \& Sefton-Green, J. (2004). Style, genre and technology: The strange case of youth culture online. In I. Snyder \& C. Beavis (Eds.), Doing literacy online: Teaching, learning and playing in an electronic world (pp. 121-144). New York, NY: Hampton Press.

Oare, S. (2012). Decisions made in the practice room: A qualitative study of middle school students' thought processes while practicing. Update: Applications of Research in Music Education, 30(2), 63-70.

Pak, M. (2014). The digital self: Boundaries and fusions. Journal of Marketing Theory and Practice, 22(2), 141.

Partti, H. (2014). Cosmopolitan musicianship under construction: Digital musicians illuminating emerging values in music education. International Journal of Music Education, 32(1), 3-18.

Partti, H., \& Karlsen, S. (2010). Reconceptualising musical learning: New media, identity and community in music education. Music Education Research, 12(4), 369-382.

Scardamalia, M., \& Bereiter, C. (2008). Pedagogical biases in educational technologies. Educational Technology, 48(3), 3-10.

Steen, M. (2013). Virtues in participatory design: Cooperation, curiosity, creativity, empowerment and reflexivity. Science and Engineering Ethics, 19(3), 945-962.

Tobias, E. S. (2014). 21st century musicianship through digital media and participatory culture. In M. Kaschub \& J. Smith (Eds.), Promising Practices in 21st Century Music Teacher Education (pp. 1-23). Oxford, UK: Oxford University Press.

Upitis, R., \& Abrami, P. C. (2016). Cadenza: An online tool for transforming music learning. The European Journal of Social and Behavioural Sciences, 1(1), 2261-2270.

Upitis, R., Abrami, P. C., \& Boese, K. (2016). The use of digital tools by independent music teachers. In I. A. Sanchez \& P. Isais (Eds.), Proceedings of the International Conference on Mobile Learning (pp. 108-112). Vilamoura, PT: International Association for the Development of the Information Society.

Upitis, R., Brook, J., Abrami, P. C., \& Varela, W. (2014). Independent music teaching in the 21st century: What teachers tell us about pedagogy and the profession. In Proceedings of the International Seminar of the ISME Commission on Research (pp. 299-315). Paraíba, BR: International Society for Music Education.

Waldron, J. (2013a). User-generated content, YouTube and participatory culture on the Web: Music learning and teaching in two contrasting online communities. Music Education Research, 15(3), 257-274.

Waldron, J. (2013b). YouTube, fanvids, forums, vlogs and blogs: Informal music learning in a convergent on- and offline music community. International Journal of Music Education, 31(1), 91-105.

Wegerif, R. (2012). Dialogic: Education for the Internet age. New York, NY: Routledge.

Wolcott, H. F. (1990). On seeking-and rejecting-validity in qualitative research. In E. W. Eisner \& A. Peshkin (Eds.), Qualitative inquiry in education: The continuing debate (pp. 121-152). New York, NY: Teachers College Press.

Yazan, B. (2015). Three approaches to case study methods in education: Yin, Merriam, and Stake. The Qualitative Report, 20(2), 134-152. 